\title{
GAME AS EDUCATIONAL NON-FORMAL METHOD
}

\author{
lonuț Mihai Oprea \\ Dr., University of Oradea, ROMANIA, oprea_ionut_mihai@yahoo.com
}

\begin{abstract}
Through the game you can highlight the child's personality, thinking and feelings. Education has a welldefined purpose and best, this aim, can be achieved through play. It is the game that makes the child understand reality. In life, we have different roles, we take up different social positions, but what is the role of adult in the non-formal game of child education? In teaching theories, adult plays a catalyst role, helping the child understand himself, understand others and understand what he or she learns.

We can believe that games and, in particular, motion games contribute to the formation of positive emotional States and moral qualities, will and character traits. They educate the child's trust in their own forces, a sense of friendship, stimulate the pleasure of acting in and for the collective. He also develops the courage, the courage, the perseverance, the spirit of competition and responsibility toward his own actions, discipline and self-control. Games capture the world's ideas on their cultures and pass them on to future generations. Games are seen as important social and cultural events as learning tools and signs of social status. Education experts describe children as a key element of their development. When a child spends a lot of time playing, it is not considered a waste of time, but a way for the child to interact with the world around him. Play the child requires neither many elements nor specialized guidance, in conditions where the child plays safely. There is no need for adult intervention. The game is the environment through which information from the real world reaches the child's mind and is the first means of directing and knowing reality.

This Article wants to bring the idea of the teaching game as an object of trust in its educational value. We must not see the game or reference it to a simple way of effortless expansion. In the course of his history, the Game manages to overcome this status, and more and more scientists are beginning to appreciate its educational virtues. Many theories have been formulated on the game. Some authors view the game as a survival exercise, for other authors the game plays a cathartic role, in downloading the negative emotions. But, through the game, the child has the authority to create a representation, to establish a flexible situational model in order to achieve emotional development..
\end{abstract}

Keywords: Game, non-formal education, children, society.

\section{INTRODUCTION}

Play can be defined as an activity characterized by participation (Zoosh et al., 2017), intrinsic involvement and motivation, using imagination, creativity but also non-verbal language, of a voluntary or freely chosen nature, personally guided, initiated by the child/children without outside rules, Incorporating fluid and active activities, sometimes guided by mental laws and high levels of meta-cognition and meta-communication (Shapiro \& Leopold, 2012), which also offers its structure, but without any extrinsic purpose, because it is centred on the process, not on the product ("What is play and when is it important for Learning?", 2019).

Game types are varied, sometimes well defined, sometimes overlapping different types of play, so categories can be independent or overlapping (O'Gorman \& Ailwood, 2012). The types of play can be exploration with objects, physical play, play role, fantasy, dramatic, intelligence games, with rules or without, of construction, language, interior and exterior. In this context, games can be split into three main categories: 
1. Free or pure games - children have full control, adults being only observers

2. Guided games - educator and child collaborate, putting the child's interests and playing ideas before the goals themselves

\section{Learning through play - the educator has control of the game.}

Free play or play guided by the child assumes that he/she chooses his/her activities and focus points in the game. The child is allowed to express himself or herself without any restrictions (Faas et al., etc.). The whole process is initiated, supported and developed only by children, without any active involvement of the educator or adult. However, the criticism of this type of game is that no matter how free it is played by the child, adults control the environment in which they operate, limiting access to certain objects or locations ("What Is Play and Why Is It Important for Learning?", 2019).

Guided play is centred on the child, but also on the lenses. It is based on the involvement of the child, exploration and observation of details, but has precisely formulated educational purposes, which is why the educator imposes limits to direct attention and reduce any distractions. The educator makes use of children's initiatives, choices, interactions and creativity, but directs them to increase knowledge, deepen understanding and develop new skills. Educators insert new goals and ideas unknown to children into the children's play (Thomas et al., 2011). However, account shall be taken of the interaction of children with new content. The educator focuses children's attention on the intended and reasonably structured pedagogical objectives (Baciu \& Peter, 2014). The comments and comments of the educator become new content for children, plus feed-back, demonstration and emphasis on the use of a particular type of vocabulary. Their aim is to help children to explore effectively and target their environment, but also to develop new skills for solving problems. The teacher-guided play contains activities chosen and imposed by the educator, which have different types of involvement as their aim. The objective of this type of play is the development of academic and knowledge skills (Cutter-Mackenzie \& Edwards, 2013), but through learning through play, fun and good mood. The whole game process is coordinated by the educator, is based on rules and goals are achieved within the well-defined time frame ("What Is Play and Why Is It Important for Learning?", 2019).

Through the game, the child is able to express the noblest emotion, namely the feeling of love (Pascariu, 2020). Play and play learning is developing throughout childhood, becoming more complex, with organizational structures with varying degrees of sophistication and social, physical and cognitive involvement. Small children engage in exploration and social games and exploration precedes play, through which the child collects information and discovers the properties and attributes of objects, situations and ideas (Edwards, 2016). Once imagination develops, play gets new values, focused on building game, role play and language play. In addition, games involving problem solving and collaboration are focused on processes, structures and results. Then play is developed on the social axis, which requires cooperation between children, to assign roles in different playground scenarios ("What Is Play and Why Is It Important for Learning?", 2019).

\section{THE BENEFITS OF NON-FORMAL GAME}

Learning through play has two basic aspects: Free play and assisted play. Play is fun, flexible, voluntary and intrinsically motivated. Play unattended is not based on any final objective and has no purpose for which the child is playing. Assisted play preserves the defining elements of the game (Moore et al., 2014), but the child is guided to a precise, observable purpose. Whether assisted or free, the fundamental element of the game is that it helps your child to get into the reality around him, with whom he interacts by developing skills ("Top 5 Benefits of Learning Through Play Blog | Chatsworth Hills Academy," 2018).

In this context, they have the following benefits for children:

1. Contributes to training communication skills: Play alone or play in a team provides the child/children with the right context for developing speech, language and listening skills. If he has no playground partners, the child will be born alone, creating his own vocabulary. Whether alone or in a group, the child creates the imagination in the game, but also its limits (Guirguis, 2018). The advantage of guided play is that you can intervene quickly and effectively in the relief of different tensions between children. Also, one of the main advantages of the guided game is that speech and language skills are developed, especially useful in disadvantaged environments.

2. Contributes to the training of social skills: Play in groups provokes children to work with a specific purpose. Even if in their organization one of them is the leader, he will learn how to listen to the ideas of others, but he will also filter their ideas. Thus, group play helps children to become assertive, negotiate, cooperate and share either their toys or their ideas (Pivec, 2007). The result of this type of play has to do with the ability to 
develop friendly relations and social skills. A major advantage of team play is the process of processing emotions. They are expressed by physical play, stories, art, but also related practical activities. Play will help them express themselves both physically and through the words they learn.

3. Contributes to the development of cognitive, driving and critical thinking skills: Critical thinking is the ability to analyse and filter information, to understand it and to apply it in a particular context. The exposure of the child to stories, and then comes to the point where he asks to hear stories, is an example of gaining critical thinking. The elements that the child learns to count and name, contribute significantly to the organization of the imaginary and real world, which the child organizes and adapts to (Greenwood et al., 2006). Physical play, especially the high intensity one, helps to combat stress and poor provision, along with the development of motor skills. First the child develops the skills of the big motor, such as running or pedalling and throwing. The skills to write and colour are then developed. In addition to the balance and hand-eye coordination. A very important subsequent skill develops when the child can eat and dress himself. This proves the ability to remain independent.

4. Contribute to the development of trust: The ability to build trust is fundamental for the child who will have to take risks later on, but also to try new things. The family environment is the one in which confidence is first developed, after which the basis of exploration is extended by discovering new environments and things, especially through own efforts. The link between the child and the parent develops throughout childhood, but with the progressive dynamics, by which the child becomes more independent (Freeman et al., 2015).

5. Contribute to the development of creativity: Creativity is the result of combining critical thinking and developing the various skills listed in the previous points, which produce something new. The imaginary game, as well as the role game, becomes the basis of the child's world, which begins around the age of 2 The child uses any object around him to create his or her imaginary universe. The objects are used because they understand the concept of symbolism. To them are added the role game, which has different varieties. By assuming their roles, the child takes shape with regard to the role he plays, exposes himself to the various features of the roles, managing to draw conclusions, which will filter out the types of role he likes (Leggett, 2017).

Specialist studies remain inconclusive on the effectiveness of learning through play. The reality of the game is too complex to draw final conclusions. Learning and play elements such as play types, play overlaps, external influences and the environment in which they are played together with adult involvement create a sufficiently complex environment to require sustained follow-up of specialist research. It is impossible to separate learning play, which is why a lot of factors that affect and develop the concept of play and learning (Edwards, 2017) must be taken into account.

In the context of recent research, it is not clear whether it is crucial for the development of the child or whether it is only a way to support development in cooperation with other children and the involvement of adults. The role of the game in learning may also depend on factors such as social intelligence and language skills. Even if there are gaps in research, play is an important environment for children's development as well as for the learning process. The knowledge, experiences and representations that take place in children's play contribute to how they find and define the meaning in the world they live in ("What Is Play and Why Is It Important for Learning?", 2019).

\section{THE LIMITS OF NON-FORMAL GAME}

The boundaries of the game are a necessity to avoid positivistic and triumphalist descriptions, which in turn could create a problematic environment for both children and adults. Children's play depends on the environment in which the child is grown up, which is why it is strongly linked to the world of adults and the limitations they impose (Barblet et al., 2016). Also, the optimistic views on the game may be erroneous or simplistic (Strauss, etc.) the importance, complexity and depth of the game and the role it plays in the development of the child and in the learning process. The criticisms focus on the following landmarks ("What Is Play and Why Is It Important for Learning?", 2019):

1. Learning can be supported by several methods - and it is not the only central element to play, especially as it is a cultural phenomenon that depends on the involvement of adults. Children copy and engage in play games, with or without the help of adults, adapting the environment to their needs.

2. Play children contains a rich and varied repertoire - the variety can be an advantage, but it can also be a disadvantage, if the home environment does not encourage a certain type of play, whereas the institutionalized environment of the kindergarten focuses on those aspects. Because of the cultural aspects of families, the learning through play experience is not universally valid, but differs from one culture to 
another and even from one family to another.

3. Children are not always able to express themselves through play - children's ability to express themselves and express their needs is limited even by play, which is why, according to the parameters of personal and family development, some children are advantageous, while others will have to recover.

4. Play is not value-neutral - which is why play is never correctly defined as "free". The impact that educators have, together with their active involvement, makes the whole process lead or guided. The Western environment is built on a certain type of values, which are presented in the children's development environment, even by playing, and sometimes have a negative impact on the relationship between the learning environment/educational institution and the child's family. Thus, a tension is created between the family and the institution, which either leads to the removal of the child from the institution or to the folding of the content to the child's cultural and spiritual needs.

5. Play can be cruel - because it can involve attars, inappropriate jokes and a whole compendium of malicious behaviour. Children can use play to promote their own interest, even at the cost of annoying or offending the playing partners.

\section{CONCLUSIONS}

The game, as we could see, presents a typological variety with roles at all stages of life. All the more so we are referring to physical development, social development, emotional development, intellectual development and the list can continue. Play is particularly important in all crops. This field of education has managed to gain its place in the house of human sciences through practical usefulness, as demonstrated in history.

Today, the teaching game is of great use in all schools around the world. The game is a multidimensional space comprising multiple situations (systematic, epistemic, metaphoric, unpredictable, etc.). The game slides between synergy and conflict, fantasy and reality, freedom and constraint, competition and cooperation and the list can continue. The game, as well as human activity, offers opportunities for learning, and it becomes motivation and pleasure.

\section{REFERENCE LIST}

Banciu, V., Peter, K., (2014), Developing communication through educational games with preschoolers, în INTED 2014 PROCEEDINGS, 8th International Technology, Education and Development Conference, Valencia, Spain, ISBN 978-84-616-8412-0, pp. 2469-2477.

Barblett, L., Knaus, M., \& Barratt-Pugh, C. (2016). The Pushes and Pulls of Pedagogy in the Early Years: Competing Knowledges and the Erosion of Play-based Learning. Australasian Journal of Early Childhood, 41(4), pp. 36-43.

Cutter-Mackenzie, A., \& Edwards, S. (2013). Toward a Model for Early Childhood Environmental Education: Foregrounding, Developing, and Connecting Knowledge Through Play-Based Learning. The Journal of Environmental Education, 44(3), pp. 195-213.

Edwards, S. (2016). New concepts of play and the problem of technology, digital media and popular-culture integration with play-based learning in early childhood education. Technology, Pedagogy and Education, 25(4), pp. 513-532.

Edwards, S. (2017). Play-based Learning and Intentional Teaching: Forever Different? Australasian Journal of Early Childhood, 42(2), pp. 4-11.

Freeman, S. F. N., Gulsrud, A., \& Kasari, C. (2015). Brief Report: Linking Early Joint Attention and Play Abilities to Later Reports of Friendships for Children with ASD. Journal of Autism and Developmental Disorders, 45(7), pp. 2259-2266.

Greenwood, C. R., Walker, D., Carta, J. J., \& Higgins, S. K. (2006). Developing a General Outcome Measure of Growth in the Cognitive Abilities of Children 1 to 4 Years Old: The Early Problem-Solving Indicator. School Psychology Review, 35(4), pp. 535-551.

Guirguis, R. (2018). Should We Let Them Play? Three Key Benefits of Play to Improve Early Childhood Programs. International Journal of Education and Practice, 6(1), pp. 43-49. 
Leggett, N. (2017). Early Childhood Creativity: Challenging Educators in Their Role to Intentionally Develop Creative Thinking in Children. Early Childhood Education Journal, 45(6), pp. 845-853.

Moore, D., Edwards, S., Cutter-Mackenzie, A., \& Boyd, W. (2014). Play-Based Learning in Early Childhood Education. In A. Cutter-Mackenzie, S. Edwards, D. Moore, \& W. Boyd (Eds.), Young Children's Play and Environmental Education in Early Childhood Education, pp. 9-24.

O'Gorman, L., \& Ailwood, J. (2012). They Get Fed up with Playing: Parents Views on Play-Based Learning in the Preparatory Year. Contemporary Issues in Early Childhood, 13(4), pp. 266-275.

Pascariu C. C., (2020), The game - The way children teach us the art of love, In ERD 2019 Education, Reflection, Development, Seventh Edition, European Proceedings of Social and Behavioural Sciences EpSBS, Chiș V., Albulescu I., Cluj-Napoca, Published by the Future Academy, ISSN: 2357-1330, pp. 625-629.

Pivec, M. (2007). Editorial: Play and learn: potentials of game-based learning. British Journal of Educational Technology, 38(3), pp. 387-393.

Shapiro, S., \& Leopold, L. (2012). A Critical Role for Role-Playing Pedagogy. TESL Canada Journal, 29(2), pag. 120.

Thomas, L., Warren, E., \& deVries, E. (2011). Play-Based Learning and Intentional Teaching in Early Childhood Contexts. Australasian Journal of Early Childhood, 36(4), pp. 69-75.

Top 5 Benefits of Learning Through Play Blog | Chatsworth Hills Academy. (2018, February 26). Granada Preparatory School. https://chaschool.org/top-5-benefits-learning-play/

What is play and why is it important for learning? (2019, November 10). THE EDUCATION HUB. https://theeducationhub.org.nz/what-is-play-and-why-is-it-important-for-learning/

Zosh, J. N., Hopkins, E., Jensen, H., Liu, C., Neale, D., Hirsh-Pasek, K., Solis, L., Whitebread, D., \& LEGO Foundation. (2017). Learning through play: A review of the evidence. 